\title{
Academics' knowledge and experiences of interprofessional education and practice
}

\author{
H Julie, ${ }^{1} \mathrm{PhD}$; L Hess-April, ${ }^{2} \mathrm{PhD}$; J Wilkenson, ${ }^{3} \mathrm{MSc}$; W Cassiem, ${ }^{4} \mathrm{PhD} ; \mathbf{A}$ Rhoda,${ }^{5} \mathrm{PhD}$ \\ ${ }^{1}$ School of Nursing, Faculty of Community and Health Sciences, University of the Western Cape, Cape Town, South Africa \\ ${ }^{2}$ Department of Occupational Therapy, Faculty of Community and Health Sciences, University of the Western Cape, Cape Town, South Africa \\ ${ }^{3}$ Department of Dietetics and Nutrition, Faculty of Community and Health Sciences, University of the Western Cape, Cape Town, South Africa \\ ${ }^{4}$ School of Natural Medicine, Faculty of Community and Health Sciences, University of the Western Cape, Cape Town, South Africa \\ ${ }^{5}$ Department of Physiotherapy, Faculty of Community and Health Sciences, University of the Western Cape, Cape Town, South Africa
}

Corresponding author: H Julie (hjulie@uwc.ac.za)

Background. Interprofessional education (IPE) can be seen as the vehicle to address the health and social problems of society through collaborative approaches. Since IPE should be facilitated by educators who are skilled in this area, faculty development initiatives should be based on the principles of IPE and collaborative practice (IPECP).

Objective. To explore academics' knowledge and experiences of IPECP.

Methods. The study used an exploratory descriptive design and the appreciative inquiry framework underpinned data gathering and analysis. The data were collected using workshops, and the participants of the workshops shared their knowledge and experiences of IPECP, which were audio-recorded and analysed using thematic analysis. Ethical clearance was obtained from the University of the Western Cape, Cape Town, South Africa.

Results. The analysis revealed three themes: knowledge of IPE; experiences of IPECP; and enablers of IPECP aligned to the dream and discovery phases of appreciative inquiry. The findings revealed that academics were knowledgeable about the concept of IPE and that their experiences with IPECP ranged from clinical supervision to research. Regarding enablers of IPECP, they provided important input, which could facilitate IPECP in a university faculty. These included competencies for IPECP, professional development and a common practice framework.

Conclusion. The academics who attended the faculty development workshops were knowledgeable about the concepts of IPECP. They concluded that for IPE to be effective, a common practice framework should be adopted in the faculty to inform specific teaching and learning strategies and outcomes.

Afr J Health Professions Educ 2016;8(2 Suppl 2):222-224. DOI:10.7196/AJHPE.2016.v8i2.845

In the context of socially responsive and politically relevant interprofessional education (IPE), the need for educators to engage more seriously with IPE has been highlighted. The underlying assumption to IPE is that enhanced collaboration between professionals will lead to better use of scarce resources and a more effective response to complex health needs.

IPE is not a new concept - the Centre for the Advancement of Interprofessional Education (CAIPE) ${ }^{[1]}$ in 1987 defined IPE as occurring 'when two or more professions learn with, from and about each other to improve collaboration and the quality of care'. The World Health Organization (WHO) recently published the Framework for Action on Interprofessional Education and Collaborative Practice. ${ }^{[2]}$ Collaborative practice can improve access to and co-ordination of health services, appropriate use of specialist clinical resources, and health outcomes. ${ }^{[3]}$

A global, independent Lancet commission stated that professional education has not kept up with contemporary health challenges. ${ }^{[4]}$ They attribute this to five factors: (i) fragmented, outdated curricula and static pedagogy that produce ill-equipped graduates; (ii) a mismatch of competencies to population needs; (iii) insufficient adaptation of education to local contexts; (iv) professions operating in silos; and $(v)$ tribalism and a lack of team spirit among professionals. The commission asserts that as a result of these factors, professionals have become mere managers of technology and are reluctant to serve marginalised communities. At the same time, they are not able to exercise effective leadership to transform health systems. The $\mathrm{WHO}^{[5]}$ therefore calls for the education of health professionals to be redesigned as IPE to facilitate the breaking down of professional silos while enhancing collaborative practice.

The underlying assumption to IPE is that enhanced collaboration between professionals will lead to better use of scarce resources and a more effective response to complex health needs. IPECP are thus regarded as strategies to transform health systems globally. ${ }^{[2]}$ According to the Lancet commission, ${ }^{[4]}$ the realisation of enhanced collaboration between professionals requires instructional and institutional reforms, which should be guided by two proposed outcomes: transformative learning and interdependence in education. ${ }^{[4]}$ They describe the essence of transformative learning as developing leadership attributes and producing enlightened change agents. Interdependence in education involves a shift from isolated to harmonised education and health systems, as well as a shift from stand-alone institutions to networks and alliances that harness educational content, teaching resources and innovations.

To facilitate this shift, the WHO highlights that educators of outstanding quality are needed to transform and upscale health professionals' education. ${ }^{[5]}$ Hence, continuous professional development initiatives, based on the principles of IPE and the healthcare need $\mathrm{s}^{[2]}$ of communities, are required to transform health professional education. Principles of IPE that should be highlighted during these IPE initiatives include values that need to be addressed when engaging in IPE, processes involved in IPE and specific IPE-related outcomes. ${ }^{[1]}$ To equip academics in IPE, educational institutions need to develop IPE communities of practice in order to champion IPECP in their respective health professional programmes. 


\section{Problem statement}

The Faculty of Community and Health Sciences (hereafter referred to as the Faculty) at the University of the Western Cape (UWC), Cape Town, South Africa has identified IPECP as a priority area for its 2015 - 2019 strategic plan. The intended outcome is to prepare health professional graduates as change agents, able to competently intervene in health issues relevant for the 21st century. Given the strategic direction of UWC and the Faculty, it is therefore important that IPECP be integrated in the academic curricula of the 10 professional disciplines located in the Faculty. A critical mass of academics (lecturers and clinical supervisors) is therefore needed to drive the process of this strategic initiative. In response to this, the Faculty implemented initiatives to: (i) develop knowledge and skills in IPE; (ii) facilitate the development of IPE communities of practice to achieve the relevant student outcomes; (iii) engage interprofessional communities to develop the skills needed to promote and facilitate collaborative leadership, IPE and team-based practice; and (iv) use innovative curricula, high-quality experiential learning and coaching (personal communication, Dr F Waggie, IPE Unit, UWC, 2015). It was therefore imperative to assess the progress the Faculty has made in terms of these IPE initiatives.

The purpose of this article is to present academics' knowledge and experiences of IPECP as explored during an IPE faculty development initiative.

\section{Methods \\ Study setting}

The Faculty offers education programmes in physiotherapy, occupational therapy, nursing, dietetics, psychology, social work, sport, recreation and exercise science, public health, and natural medicine. All departments provide 3- or 5-year professional degree programmes at undergraduate level with a focus on primary healthcare (PHC) and community development. The IPE unit presents interprofessional courses that form part of the curriculum of all disciplines and all year levels in the Faculty. Apart from the undergraduate degree programmes, the Faculty offers a range of postgraduate qualifications such as certificates, diplomas, Master's and doctoral degrees. Usually, dentistry is considered part of a health sciences faculty, but at UWC dentistry forms its own a faculty.

\section{Study design}

The study used an exploratory descriptive research design. ${ }^{[6]}$ Appreciative inquiry was the philosophical stance that underpinned the methodological processes of data gathering and analysis. ${ }^{[7]}$ The appreciative inquiry process $^{[8]}$ involves four movements: (i) discovery (i.e. defining the concept and discovering what has worked); (ii) dreaming (i.e. envisioning what could be); (iii) design (i.e. prioritising and planning what should be); and (iv) destiny (i.e. developing a model based on identified priorities). Inviting Faculty members to collaborate within an appreciative inquiry framework in a workshop setting, where participants inquire into a specific topic or issue in which they have some vested ownership, can result in transformational changes in very short time frames. ${ }^{[9]}$

The objective of the study was to explore the academics' knowledge of the IPE concept and their IPE experiences. This exploration was conducted through an appreciative lens in that the positive aspects of IPE-related activities of the Faculty were highlighted. These baseline data were needed to facilitate the design and development of a Faculty IPECP model by engaging academics in the 'discovery' and 'dreaming' cycles of appreciative inquiry.

\section{Population and sample}

The study population comprised the academics (lecturers and clinical supervisors) from the 11 departments and schools that constitute the Faculty at UWC. The population also included academics from the Faculty of Dentistry, School of Pharmacy and other higher education institutions who expressed prior interest in IPE. Data were collected from a convenience sample of 30 participants from the different health science disciplines who participated in Faculty development workshops (Table 1).

Table 1. Representatives attending the faculty academic development workshops on 4 June and 18 September 2015

\begin{tabular}{ll}
\hline Constituency & Representatives, $\boldsymbol{n}$ \\
\hline Deanery of the Faculty of Community Health Sciences & 2 \\
Dietetics & 2 \\
Dentistry and Oral Health & 2 \\
External higher education institutions & 2 \\
Interdisciplinary Teaching and Learning Unit & 2 \\
Nursing & 2 \\
Natural Medicine & 8 \\
Occupational Therapy & 2 \\
Pharmacy & 2 \\
Physiotherapy & 2 \\
Social Work & 3 \\
Teaching and learning specialist & 1 \\
Total & 30
\end{tabular}

\section{Data collection method and process}

This study forms part of a larger study that received ethical clearance from the UWC Research Ethics Committee (no. 13/3/9).

Two Faculty development workshops, offered on 4 June and 18 September 2015 at the UWC campus, were used for the purpose of data collection. The stated purpose of these workshops was to contribute to strengthening and refining the ongoing discourse among academics on IPECP in the Faculty. The workshops consisted of a number of presentations by keynote speakers. After the didactic input, the workshop participants were divided into smaller interprofessional groups and were asked to share their understanding and experiences of IPE. Two main issues were probed by facilitators during the group discussions: (i) participants' understanding of IPE; and (ii) participants experiences of IPECP. The presentations on these issues from the small-group work and subsequent plenary workshop discussions were audio-recorded and transcribed verbatim. Sensitised by the principles of appreciative inquiry, we conducted data analysis of these transcripts, following an inductive process of thematic analysis, where data were read and reread, coded and categorised into themes ${ }^{[7]}$ As proposed by Braun and Clarke, ${ }^{[10]}$ thematic analysis, which involves the identification of themes or intersecting patterns in qualitative data, was used to analyse the data. This allowed for in-depth and direct data examination and consideration of the different meanings of participants' experiences and perspectives, from which emerging patterns and themes could be generated. ${ }^{[7]}$ The initial themes and codes were validated by three independent coders and consensus was reached regarding the analysis. 


\section{Results}

The results of the first two steps of the appreciative inquiry framework that highlighted the participants' conceptual understanding of the concept and previous experiences with IPE (discovery), and their suggestions for what could be (dreaming), are presented. The data analysis revealed three major themes and related categories: (i) knowledge of IPE; (ii) experiences of IPECP; and (iii) enablers of IPECP (summarised in Table 2).

\section{Theme 1: Knowledge of IPE}

In probing the issue of the participants' knowledge of IPE, their conceptual understanding of the concept and previous experiences with IPE emerged. They alluded to the principles and value of IPE.

\section{Principles of IPE}

In relation to principles of IPE, collaborative teamwork and common client outcomes were foregrounded:

'Working together as a team of health professionals to solve a problem or develop common client-centred outcomes.'

'Learning with, from and about each other, and putting this new knowledge into practice.'

\section{Values of IPE}

By referring to a collapsing of professional and territorial hierarchies, the participants appeared to be cognizant of the values of IPE:

'Having a basic understanding of various healthcare disciplines with joint intervention adopting a holistic approach to the management of a patient, without prejudice towards the next discipline or reluctance to refer'.

\section{Theme 2: Experiences of IPECP}

From the participants' responses, it was clear that they had diverse experiences with IPECP. These experiences included those encountered during joint teaching and learning, clinical practice and research.

\section{Teaching and learning}

Participants highlighted their involvement in the Faculty-based interprofessional modules and interprofessional community-based projects:

'I have been involved directly in teaching interdisciplinary modules and supervising students in the interprofessional community-based programmes ... facilitating interdisciplinary principles and practice.'

Table 2. Summary of themes and categories

\begin{tabular}{lll}
\hline Theme 1: Knowledge of IPE & Theme 2: Experiences of IPECP & Theme 3: Enablers of IPECP \\
\hline Principles of IPE & Teaching and learning & Competencies for IPECP \\
Value of IPE & Clinical practice & Professional development \\
& Research & Common practice framework
\end{tabular}

Most participants also participated in the planned interprofessional teaching and learning activities co-ordinated by the IPE Unit on campus:

'I attended the world café last year and this year with my students.'

\section{Clinical practice}

The participants experienced IPECP in different practice settings. Hospitals were highlighted as an example where IPE was experienced in an institution:

'We have monthly [multidisciplinary team] MDT meetings, experienced it at ... hospital with medical doctors, a case would be discussed and input from various professionals given.'

Interprofessional community-based practice experiences were also highlighted:

'I experienced it in [the community], with natural medicine practitioners and nurses and community health workers.'

\section{Research}

In addition, the participants referred to the interprofessional research projects they engaged in:

'We also conduct collaborative research in different specialisations .... ?

\section{Theme 3: Enablers of IPECP}

Enablers of IPECP appeared to be a natural outflow from the participants' reflections regarding their experiences of IPECP. They highlighted that for IPE to be effective, enablers such as competencies for IPECP and the professional development of academics and clinical educators, as well as a common practice framework, are needed.

\section{Competencies for IPECP}

With regard to facilitation of competencies, participants articulated that these competencies need to be explicit:

'Competencies for [interprofessional practice] IPP need to be explicit ... maybe, there is a competency to be able to work as a team ... there definitely needs to be competencies that are explicit about working with other healthcare professionals.'

\section{Professional development}

The participants also expressed the need for continuous professional development in the area of IPECP. They stressed that competencies need to be facilitated through appropriate teaching and learning strategies, where IPE outcomes are included in the planning of curricula:

'There is a need for an IPE and IPP induction course just to bring everybody [on board] ... to create awareness and [shared] understanding of IPE [and for] ... capacity building of academics [lecturers] and clinical supervisors.'

Participants identified that there are opportunities for collaborative practice to be role-modelled at certain clinical placements but academics need to work with clinical supervisors to harness these opportunities:

'For instance at hospital ... nursing, [occupational therapy] OT and [physiotherapy] physio students could use the opportunities for IPE ... in this way our supervisors could be trained to drive the agenda so that in our thinking, planning and practice we get it right ... to design IPE opportunities [that are] authentic [in] clinical learning environments [to allow for] interprofessional role modelling.'

\section{Common practice framework}

Participants further identified the need to adopt a common language and practice framework for IPECP to be successful. Two frameworks mentioned were the International Classification of Functioning, Disability and Health (ICF) and PHC:

'The one thing that we need to be common is the language, and that is the aim of the ICF, so that we speak and understand the common language of the framework within all the professions.'

'If we look at PHC ... we speak about the district health system, we meet individual need, we need to meet population need as well ... it is about looking at something [a framework] that we can develop that is common for us, for our faculty. 
The participants further related the use of a common practice framework to specific outcomes for IPECP:

'There must be outcomes phrased around IPE and IPP, that need to be explicit, so we need to write that as part of our [curriculum] ... our training for our students'.

It was also highlighted that buy-in from service partners would be crucial to the successful facilitation of IPECP competencies:

'People need to understand how IPP can benefit the community at large, so yes, we will have to engage with the management of these services where our students practise and get IPP on their agenda.'

In discussing the relevance of the ICF and PHC frameworks, the participants articulated that competencies related to the ethos of UWC need to be incorporated into IPECP and the specific teaching and learning strategies adopted:

'A shortcoming of both frameworks is the issue of power ... where you have to deal with structural and systemic barriers to social justice ... should political adeptness and understanding power dynamics be competencies that we want our students to develop through IPE?'

\section{Discussion}

Within an appreciative inquiry framework, this article aimed to present the experiences of academics regarding IPECP. The motivation for the study was the ever-expanding evidence that exists on the value of IPE in improving attitudes and perceptions, as well as knowledge and skills, collaboratively.

In exploring participants' knowledge and experiences of IPE (discovery), their knowledge of the principles of IPE, ${ }^{[2]}$ such as responsiveness to clients' needs, as well as the use of each profession's distinctive contributions to learning and practice, were highlighted in the findings. It further emerged that the academics were knowledgeable about values of IPE, such as respect for diversity and the setting aside of differences in power and status between professions. If academics are knowledgeable, or at least aware, of the principles and values of IPE, it could provide momentum to its implementation. ${ }^{[1]}$ In addition to this, the facilitation of collaborative practice actions towards the delivery of healthcare services could also be enhanced. ${ }^{[12]}$ While the participants' experiences of IPECP ranged from educating students, both as supervisors and academics, to joint clinical practice at both a community- and institution-based level, to collaborative research, they did not elaborate on the actual quality of these experiences, but appeared to be more focused on reflecting on how IPECP could be enhanced.

Hence, in their expression of what could be (dreaming), the participants offered suggestions for the enablement of IPECP in the Faculty. They indicated that competencies for IPECP need to be clearly defined. They further suggested that capacity development of academics (both lecturers and supervisors), and role-modelling of interprofessional collaborative practice behaviours, would benefit the Faculty IPE strategy. Furthermore, the need for a common Faculty model or practice framework to drive IPE was identified. These strategies are corroborated by the findings of a systematic review, which identified that curriculum, leadership, resources, student diversity, teaching and accreditation are important challenges for IPE in developing and developed countries ${ }^{[13]}$ Implementing a competency framework, based on the competencies of teamwork, responsibilities, communication, learning, patient focus and ethics, could assist the Faculty in setting explicit competencies for the implementation of IPECP. ${ }^{[1]}$ Easing the framework into the curriculum by capitalising on what already exists, effective communication, respect for others and shared decision-making, as well as collaborative leadership, problem-solving and conflict resolution, are also important considerations. ${ }^{[11]}$

Practical suggestions for the enablement of IPE in the Faculty included providing students with authentic learning environments, evident in suggestions for the inclusion of collaborative practice outcomes for community-based clinical placements, and for the buy-in of IPECP from the management teams of these placements. These enablers are imperative, as the task of the educator is to create a natural learning environment, where the critical thinking skills and desired outcomes ${ }^{[14]}$ related to critical practice skills are embedded into authentic learning tasks. ${ }^{[14]}$ Hence, through implementation of interprofessional learning opportunities and assessment in IPE ${ }^{[14]}$ authentic learning experiences for producing desired student outcomes are increased ${ }^{[14]}$ and interprofessional readiness addressed. ${ }^{[13]}$ Students are expected to function in teams, help one another learn, and be self-directed, meaning that students become active participants in their own process of learning. ${ }^{[13]}$

In further elaborating on what could be, the findings also highlighted that the participants perceived transformative learning as central to IPE. In relation to this, the facilitation of graduate competencies and attributes with regard to social justice and being agents of change were also highlighted. This concurs with the views of the Lancet commission, ${ }^{[4]}$ which proposed not only authentic practice experiences in IPP but also transformative learning as important teaching and learning approaches in IPE.

\section{Conclusion}

The exploration of academics' knowledge and experiences of IPE generated an understanding of important considerations for the development and progression of IPECP in the Faculty. They concluded that for IPE to be effective, the outcomes and competencies for IPECP need to be clear and that a common practice framework should be adopted within the Faculty to inform specific teaching and learning strategies and outcomes.

\section{References}

1. Iroku-Malize T, Matson C, Freeman J, McGrew M, David A. Interprofessional education. Ann Fam Med 2013;11(2):188-189. DOI:10.1370/afm.1523

2. World Health Organization. Framework for Action on Interprofessional Education and Collaborative Practice. Geneva: WHO, 2010. http://www.who.int/hrh/nursing_midwifery/en/ (accessed 19 July 2016).

3. Interprofessional Ambulatory Care Unit, Edith Cowan University. Interprofessional learning. Impact of health care teams on patient outcomes. IACU, Edith Cowan University, 2012:1-30. https://www.ecu.edu.au/communityengagement/health-advancement/interprofessional-ambulatory-care-program/interprofessional-learning/iplengagement/health-advancement/interprofessional-ambulatory-care-program/interprofession
through-simulation/impact-of-health-care-teams-on-patient-outcomes (accessed 21 July 2016).

through-simulation/impact-of-health-care-teams-on-patient-outcomes (accessed 21 fuly 2016).

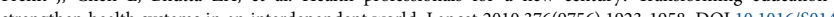
strengthen health systems in an interdependent world. Lanct 2010,376(9756).1923-1958. DO.10.1016/50140-

. World Health Organization. Transforming and Scaling Up Health Professionals' Education and Training: World Health Organization Guidelines 2013. Geneva: WHO, 2013. http://apps.who.int/iris/handle/10665/93635 (accessed 19 July 2016).

6. Lambert V, Lambert C. Qualitative descriptive research: An acceptable design. Pac Rim Int J Nurs Res Thai 2012;16(4):255-256.

7. Naude L, van den Bergh TJ, Kruger IS. 'Learning to like learning': An appreciative inquiry into emotions in education. Soc Psychol Educ 2014;17(2):211-228. DOI:10.1007/s11218-014-9247-9

8. Cooperrider DL. A contemporary commentary on appreciative inquiry in organizational life. Adv Appreciative Inq 1987;1:129-169.

9. Shuayb M, Sharp C, Judkins M, Hetherington M. Using Appreciative Inquiry in Educational Research: Possibilities and Limitations. Berkshire: National Foundation for Educational Research, 2009:1-8. http://www. nfer.ac.uk/publications/AEN01/AEN01.pdf (accessed 19 July 2016).

10. Braun V, Clarke V. Using thematic analysis in psychology. Qual Res Psychol 2006;3(2):77-101. Braun V, Clarke V. Using the

1. Kwan D, Barker KK, Austin Z, et al. Effectiveness of a faculty development program on interprofessiona

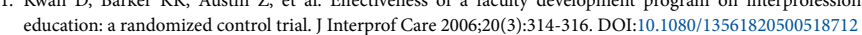
education: a randomized control trial. J Interprof Care 2006;20(3):314-316. DOI:10.1080/13561820500518712
2. Reeves S, Fletcher S, Barr H, et al. A BEME systematic review of the effects of interprofessional education: BEME 12. Reeves S, Fletcher S, Barr H, et al. A BEME systematic review of the effects of interpro
guide No. 39. Med Teach 2016;38(7):656-668. DOI:10.3109/0142159x.2016.1173663

13. Sungunya BF, Hinthong W, Jimba M, Yasuoka J. Interprofessional education for whom? - Challenges and lessons learned from its implementation in developed countries and their application to developing countries: A systematic review. PLoS ONE 2014;9(5):e96724. DOI:10.1371/journal.pone.0096724

14. Fain EA, Kennel B. Authentic learning and multifaceted assessment utilizing interprofessional collaborative learning events. World Fed Occup Ther Bull 2016;8:1-5. DOI:10.1080/14473828.2016.1152730 